\title{
Complexation and Interchromophoric Interactions in Self-Organized Porphyrin and Chlorin Triads
}

\author{
Andrei V. Chernook, Alexander M. Shulga, and Eduard I. Zenkevich \\ Institute of Molecular and Atomic Physics, Academy of Sciences of Belarus, 70 F. Skaryna Avenue, \\ Minsk 220072, Belarus \\ Ulrich Rempel and Christian von Borczyskowski* \\ Institut für Physik, Technische Universität Chemnitz, 09107 Chemnitz, Germany
}

Received: April 18, 1995; In Final Form: August 29, $1995^{\otimes}$

\begin{abstract}
Spectral properties and equilibrium constants of multimolecular complexes (triads) formed by 2-fold coordination of dipyridyl-substituted free bases of porphyrin, chlorin, or tetrahydroporphyrin with Zn-porphyrin and $\mathrm{Zn}$-chlorin dimers bridged by either of two different spacers between the monomeric entities have been studied in methylcyclohexane at room temperature. The ability of the dimers bridged by a $-\mathrm{CH}_{2}-\mathrm{CH}_{2}-$ spacer to form complexes with the free bases is found to be much lower than that for the dimers with a phenyl spacer having complexation constants up to $K_{\mathrm{C}}=5 \times 10^{7} \mathrm{M}^{-1}$. The complexation equilibrium is also affected strongly by the chemical nature of the free base and the position of the pyridyl substituents. Spectral effects occurring upon complexation in absorption spectra of the dimers are mainly due to ligation effects. Strong quenching of the dimer fluorescence in the complexes is attributed to effective singletsinglet energy transfer (ET) to the ligands.
\end{abstract}

\section{Introduction}

During the last decade growing interest has been directed toward the investigation of chemical oligomers of porhyrins or chlorophylls. In these arrays various monomer units have been covalently linked with each other in various ways or attached to subunits, being electron donors or acceptors. Synthesis and investigation of the systems have been stimulated by the fact that they are well suited for modeling excitation energy transfer and electron transport mechanisms of natural chlorophyll complexes $^{1-3}$ as well as the allosteric effects in hemoglobin., ${ }^{4,5}$ An alternative approach to the creation of complex models is based on principles of supramolecular chemistry ${ }^{6,7}$ exploiting a coordination, hydrogen bonding, or Coulombic interaction of charged species.

We have already reported on the realization of such systems made up of $\mathrm{Zn}$-tetraphenylporphyrin dimers (ZnTPP) $)_{2}$ and dipyridyl-substituted free base porphyrins. ${ }^{8}$ Two-fold coordination of the nitrogen atoms of the pyridyl substituents as axial extra-ligands to the central zinc ions of the $\mathrm{Zn}$ - porphyrin dimer subunits has been functionalized to form these complexes. The formation process has been followed by a change of absorption and fluorescence spectra of $(\mathrm{ZnTPP})_{2}$ in solution upon addition of the ligand. Complexation constants of up to $10^{8} \mathrm{M}^{-1}$ have been found in cyclohexane solutions at room temperature.

In the present work, for the sake of a systematic study of the principal properties of such complexation processes we extended our investigations to other $\mathrm{Zn}$-porphyrin and $\mathrm{Zn}-$ chlorin dimers and free bases. We discuss the impact of the chemical structure of the components on the stereospecific formation of the triads, their stability, and the electronic coupling between the subunits.

\section{Experimental Section}

1,4-Bis $\{[$ zinc(II) $] \quad 5-(10,15,20-T r i s(p$-hexylphenyl)porphyrinyl)\}benzene, $(\mathbf{Z n H T P P})_{2}$. For the preparation of the

\footnotetext{
${ }^{\otimes}$ Abstract published in Advance ACS Abstracts, December 15, 1995.
}

dimer, we used the method developed for the synthesis of tetrameso-substituted porphyrins. ${ }^{9}$ Pyrrole ( $\left.1 \mathrm{~g}, 0.015 \mathrm{~mol}\right)$, 4-hexylbenzaldehyde diethyl acetal $(2.95 \mathrm{~g}, 0.011 \mathrm{~mol})$ and tetraphtaldialdehyde $(0.26 \mathrm{~g}, 0.002 \mathrm{~mol})$ were added to $1 \mathrm{~L}$ of dry chloroform under a slow steady stream of argon. After $30 \mathrm{~min}$ $1.9 \mathrm{~mL}$ of trifluoroacetic acid was added, and the solution was stirred at room temperature for $2 \mathrm{~h}$. Then $p$-chloranil $(3.5 \mathrm{~g})$ was added, and the solution was refluxed for $2 \mathrm{~h}$. Then the solution was washed with water, filtered, and dried under vacuum. Portions ( $1 \mathrm{~g}$ ) of the precipitation were dissolved in $20 \mathrm{~mL}$ of chloroform, followed by the addition of hexane (150 $\mathrm{mL}$ ). After filtration, to remove solid impurities, the combined filtrates were evaporated and the residue was dissolved in chloroform $(32 \mathrm{~mL})$. Hexane $(80 \mathrm{~mL})$ was added, and the solution was chromatographed on silica gel (230-400 mesh, Merck) using two columns $(3 \times 30 \mathrm{~cm})$. At first the columns were eluated with a chloroform-hexane mixture (1:3) for the elution of 5,10,15,20-tetrakis(4-hexylphenyl)porphyrin (385 mg) and then by chloroform-hexane mixtures (1:2 and 1:1.5) for the dimer elution. The dimer fraction was boiled with zinc acetate in a chloroform-methanol mixture, evaporated, dissolved in benzene, and exposed to daylight until the absorption band of the chlorin admixture disappeared. ${ }^{10}$ Following the chromatography on $\mathrm{Al}_{2} \mathrm{O}_{3}$ (IV activity grade) with benzene, 32 $\mathrm{mg}(1 \%)$ of (ZnHTPP $)_{2}$ was obtained from crystallization in a chloroform-methanol mixture. $\mathrm{UV}-$ vis $\lambda_{\max }\left(\mathrm{C}_{6} \mathrm{H}_{6}\right), \mathrm{nm}(\epsilon$ $\left.\left(10^{3} \mathrm{M}^{-1} \cdot \mathrm{cm}^{-1}\right)\right): 423$ (564), 433 (682), 552 (50.8), 592 (14.9). ${ }^{1} \mathrm{H}$ NMR $\left(200 \mathrm{MHz}, \mathrm{CDCl}_{3}\right): \delta 9.42,9.18,9.03$, and 9.01 (all $\mathrm{d}, J=4.8 \mathrm{~Hz}, 16 \mathrm{H}$, pyrrole $\mathrm{H}), 8.63$ (s, 4H, 5,5'-Ph), 8.21, 7.61 (both d, 16H, 10, 20, 10', 20'-Ph, o-, m-H), 8.16, 7.58 (both d, 8H, 15,15'-Ph, o-, m-H), 3.00, 2.97, 1.96, 1.57, 1.50 (all m, 6( $\left(\mathrm{CH}_{2}\right)_{5}, 1.01,1.00$ (both t, $\left.6 \mathrm{CH}_{3}\right)$. Mass: $\mathrm{m} / \mathrm{z} 1779$ (calcd for $\mathrm{C}_{118} \mathrm{H}_{122} \mathrm{~N}_{8}{ }^{64} \mathrm{Zn}_{2}$ 1778.98).

1,4-Bis[5-(2,3,7,8,12,13,17,18-octaethylporphyrinyl)]benzene, (OEP) $)_{2}$ Ph. 1,19-Dideoxy-2,3,7,8,12,13,17,18-octaethylbiladiene- $a c^{11,12}(50 \mathrm{mg}, 0.073 \mathrm{mmol})$ and terephthalaldehyde (24 mg, $0.18 \mathrm{mmol}$ ) were dissolved in $6 \mathrm{~mL}$ of $95 \%$ ethanol. 
The solution was refluxed for $1.5 \mathrm{~h}$ under Ar. After that, $50 \mathrm{~g}$ more of octaethylbiladiene- $a c$ was added, and the solution was boiled again for $1.5 \mathrm{~h}$. The same procedure was repeated two times. (Totally, $200 \mathrm{mg}$ of octaethylbiladiene- $a c$ was spent.) $\mathrm{I}_{2}(100 \mathrm{mg})$ in ethanol was added, and the solution was then neutralized with triethylamine and diluted with water. The precipitate was collected by filtration, washed with water, and dried. Then the product was redissolved in a mixture of benzene-chloroform (2:1) and chromatographed on a $2.5 \times$ $20 \mathrm{~cm}$ column of silica gel. The column was washed with benzene- $\mathrm{CHCl}_{3}$ (2:1) to elute 5-(4-formylphenyl)octaethylporphyrin $(24 \mathrm{mg})$ and its diethyl acetal $(12 \mathrm{mg})$, followed by the benzene-chloroform-ether (40:20:1) mixture to elute the dimer. The product was collected and recrystallized from $\mathrm{CHCl}_{3} / \mathrm{MeOH}$ to give the product as red crystals, $34 \mathrm{mg}(20 \%)$. $\mathrm{UV}-\mathrm{vis} \lambda_{\max }\left(\mathrm{C}_{6} \mathrm{H}_{6}\right), \mathrm{nm}\left(\epsilon\left(10^{3}, \mathrm{M}^{-1} \cdot \mathrm{cm}^{-1}\right)\right): 415$ (351), 507 (34.1), 539 (13.3), 577 (13.2), 626 (4.9). ${ }^{1} \mathrm{H}$ NMR (360 MHz, $\mathrm{CDCl}_{3}$ ): $\delta 10.23(\mathrm{~s}, 4 \mathrm{H}$, meso), 9.92 (s, $2 \mathrm{H}$, meso), 8.62 (s, $4 \mathrm{H}, \mathrm{Ph}$ ), 4.16, 4.13, 4.08 (all q, $24 \mathrm{H}, \mathrm{CH}_{2} \mathrm{CH}_{3}$ ), 3.52 (q, $8 \mathrm{H}$, $\mathrm{CH}_{2} \mathrm{CH}_{3}$ ), 1.95, 1.94, 1.91 (all t, $36 \mathrm{H}, \mathrm{CH}_{2} \mathrm{CH}_{3}$ ), 1.44 (t, $12 \mathrm{H}$, $\mathrm{CH}_{2} \mathrm{CH}_{3}$ ), -2.61 (br s, $2 \mathrm{H}, \mathrm{NH}$ ), -2.78 (br s, $2 \mathrm{H}, \mathrm{NH}$ ). Mass: $\mathrm{m} / \mathrm{z} 1143$ (calcd for $\mathrm{C}_{78} \mathrm{H}_{94} \mathrm{~N}_{8}{ }^{64} 1142.8$ ). The $\mathrm{Zn}$ derivative of the dimer $(\mathrm{ZnOEP})_{2} \mathrm{Ph}$ was produced under the usual conditions. ${ }^{13}$

The synthesis, identification methods, and main properties of $\mathrm{Zn}$-octaethylporphyrin dimers in which the monomer subunits are linked via meso-positions by a $-\mathrm{CH}_{2}-\mathrm{CH}_{2}-$ group, 1,2-bis\{5-[zinc(II) octaethylporphyrinyl]\}ethane, $(\mathrm{ZnOEP})_{2}$, have been described in refs 14 and 15 . Dimers of $\mathrm{Zn}-$ octaethylchlorin with a $-\mathrm{CH}_{2}-\mathrm{CH}_{2}-$ spacer at meso-positions, 1,2-bis $\{\gamma$-[zinc(II) octaethylchlorinyl] $\}$ ethane, $(\mathrm{ZnOEChl})_{2}$, have been synthesized by a modification of the method described in refs 14 and 16. Free bases of porphyrin, chlorin, and tetrahydroporphyrin, varying in the position of the nitrogen atom (meta or para) in the pyridyl substituents as well as in the position of the substituents with respect to each other, have been synthesized and purified according to known methods. ${ }^{17,18}$

Figure 1 shows the chemical structures of the compounds under investigation. The evaluated distances between $\mathrm{Zn}$ ions of dimers $(d)$ and those between possible sites of ligation (nitrogen atoms of the pyridyl rings) for various pyridylsubstituted free bases $(l)$ are also presented in the figure. The estimations were performed using Draiding structural models, computer-aided structure simulation (Hyperchem software), and X-ray data for porphyrin crystals. ${ }^{19}$ Apart from the distance between the nitrogen atoms of the pyridyl substituents we took into account the length and geometry of the coordination orbital of the $\mathrm{Zn}$ ion and the pyridyl nitrogen lone pair orbitals.

All experiments have been performed using methylcyclohexane (MCH) as a solvent at room temperature. As the solubility of the dipyridyl-substituted free bases under investigation was too low in $\mathrm{MCH}$, they were predissolved in $\mathrm{CH}_{2} \mathrm{Cl}_{2}$ (up to $25 \%$ of total volume of the solution). After the titration procedure the concentration of $\mathrm{CH}_{2} \mathrm{Cl}_{2}$ in the resultant solution was less than 2 vol \%. All solvents (Aldrich spectroscopic grade) were used without further purification.

Mass spectra were recorded on a MAT 711 spectrometer by the EI method. ${ }^{1} \mathrm{H}$ NMR spectra were measured with Bruker WM-200 and WM-360 spectrometers with $\mathrm{Me}_{4} \mathrm{Si}$ (TMS) as an internal standard. Absorption spectra were recorded on a Shimadzu UV240 or Beckmann 5270 spectrophotometer. Fluorescence and fluorescence excitation spectra were measured on a Shimadzu RF 540 or SLM 4800 spectrofluorimeter and corrected by energy of emission. Table 1 presents the maxima
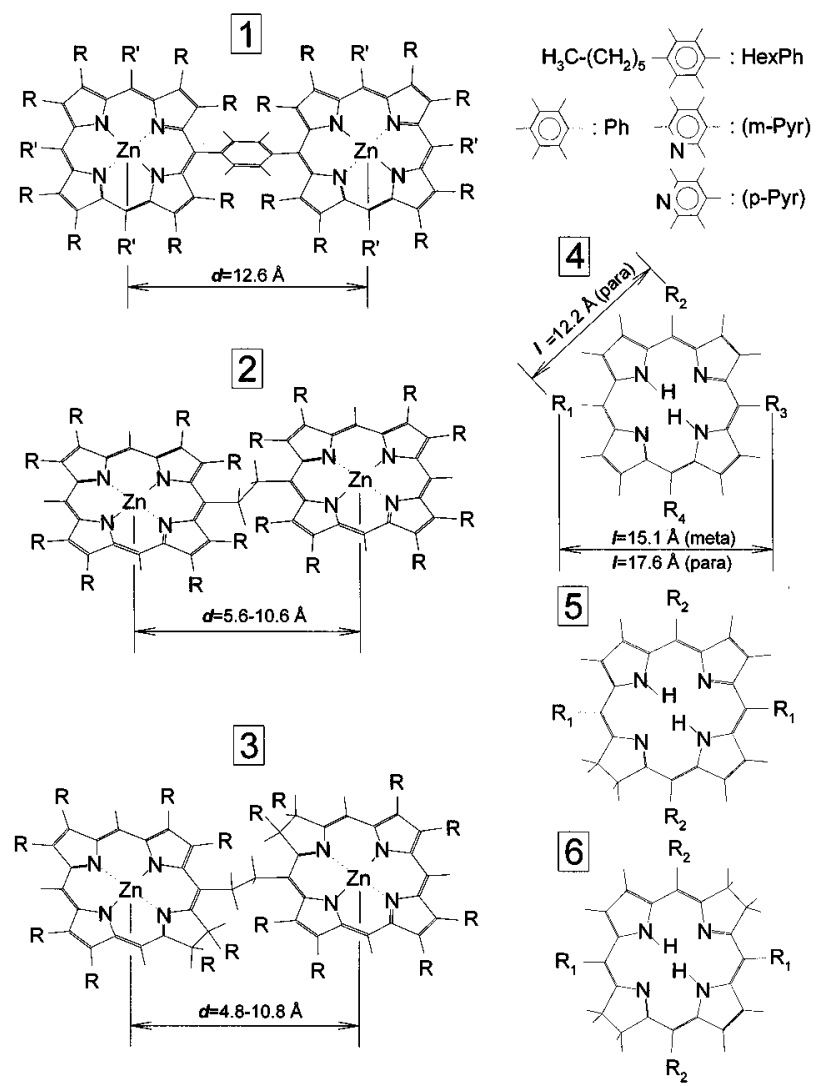

Figure 1. Chemical structures of the compounds under investigation with indicated distances between central $\mathrm{Zn}$ ions $(d)$ in the dimers and nitrogen atoms of the pyridyl substituents $(l)$ in the free bases used: (1) $(\mathrm{ZnHTPP})_{2}, \mathrm{R}=\mathrm{H}, \mathrm{R}^{\prime}=\mathrm{HexPh} ;(\mathrm{ZnOEP})_{2} \mathrm{Ph}, \mathrm{R}=\mathrm{C}_{2} \mathrm{H}_{5}, \mathrm{R}^{\prime}=$ $\mathrm{H}$; (2) $(\mathrm{ZnOEP})_{2}, \mathrm{R}=\mathrm{C}_{2} \mathrm{H}_{5}$; (3) $(\mathrm{ZnOEChl})_{2}, \mathrm{R}=\mathrm{C}_{2} \mathrm{H}_{5}$; (4) $\mathrm{H}_{2} \mathrm{P}(m-$ Pyr $)_{2}, \mathbf{R}_{1}, \mathbf{R}_{3}=(m-\mathrm{Pyr}), \mathbf{R}_{2}, \mathbf{R}_{4}=\mathrm{Ph} ; \mathrm{H}_{2} \mathrm{P}(m \wedge \mathrm{Pyr})_{2}, \mathbf{R}_{1}, \mathbf{R}_{2}=(m-\mathrm{Pyr})$, $\mathrm{R}_{3}, \mathrm{R}_{4}=\mathrm{Ph} ; \mathrm{H}_{2} \mathrm{P}(p \wedge \mathrm{Pyr})_{2}, \mathrm{R}_{1}, \mathrm{R}_{2}=(p-\mathrm{Pyr}), \mathrm{R}_{3}, \mathrm{R}_{4}=\mathrm{Ph} ; \mathrm{H}_{2} \mathrm{P}(p-$ Pyr $)_{2}, \mathrm{R}_{1}, \mathrm{R}_{3}=(p-\mathrm{Pyr}), \mathrm{R}_{2}, \mathrm{R}_{4}=\mathrm{Ph}$; (5) $\mathrm{H}_{2} \mathrm{Chl}(m-\mathrm{Pyr})_{2}, \mathrm{R}_{1}=(m-$ Pyr $), \mathrm{R}_{2}=\mathrm{Ph}$; (6) $\mathrm{H}_{2} \mathrm{THP}(m-\mathrm{Pyr})_{2}, \mathrm{R}_{1}=(m-\mathrm{Pyr}), \mathrm{R}_{2}=\mathrm{Ph}$.

of the absorption spectra and molar decimal extinction coefficients of the compounds under investigation.

Complexation constants have been obtained by the conventional technique (see, for example, ref 4 ) on the basis of both absorption and fluorescence data measured in the titration experiments. All calculations have been performed using the following formula:

$$
K_{\mathrm{C}}=\frac{[\text { triad }]}{[\text { dimer][ligand }]}=\frac{(1-\beta)}{C_{\mathrm{D} 0} \beta(x+\beta-1)}
$$

where $K_{\mathrm{C}}$ is the complexation constant; [triad], [dimer], and [ligand] are the concentrations of the complex, uncomplexed dimer, and uncomplexed ligand in the titration solution, respectively; $C_{\mathrm{D} 0}$ is the initial concentration of the dimer; $x=$ $C_{\mathrm{L}} / C_{\mathrm{D} 0}$ with $C_{\mathrm{L}}$ as the total experimental concentration of the ligand in the solution; $\beta$ is the portion of the uncomplexed dimer molecules which can be derived from the absorption of the complex, $\beta=1-D / D_{\max }$, or from the fluorescence of the uncomplexed dimer, $\beta=I / I_{0} ; D$ and $D_{\max }$ are the measured and maximum (i.e. estimated for the complete complexation of dimers in the solution) integral optical densities of the complex in the titration solution, respectively; $I$ and $I_{0}$ are the measured and initial integral fluorescence intensities of the uncomplexed dimer in the titration solution, respectively.

A typical example of a titration experiment followed by absorption is shown in Figure 2 for complexation of (ZnHTPP) with $\mathrm{H}_{2} \mathrm{P}(m-\mathrm{Pyr})_{2}$. Optical density was integrated over the range 
TABLE 1: Wavelengths $(\lambda)$ of Absorption Maxima and Extinction Coefficients $(\epsilon)$ of the Dimers, Ligands, and Their Complexes in MCH at $298 \mathrm{~K}$

\begin{tabular}{|c|c|c|c|c|c|c|c|}
\hline \multirow{2}{*}{$\frac{\text { no. }}{1}$} & \multirow{2}{*}{$\begin{array}{r}\text { compound } \\
\mathrm{H}_{2} \mathrm{P}(m-\mathrm{Pyr})_{2}{ }^{a}\end{array}$} & \multicolumn{6}{|c|}{$\lambda(\mathrm{nm}) / \epsilon\left(10^{3} \mathrm{M}^{-1} \cdot \mathrm{cm}^{-1}\right)^{h}$} \\
\hline & & $417 / 460$ & & $513 / 19.9$ & $546 / 8.4$ & $591 / 5.6$ & $652 / 4.5$ \\
\hline 2 & $\mathrm{H}_{2} \mathrm{Chl}(m-\mathrm{Pyr})_{2}{ }^{b, d}$ & $416 / 190$ & & $516 / 16.0$ & $543 / 12.0$ & $599 / 6.1$ & $653 / 42.0$ \\
\hline 3 & $\mathrm{H}_{2} \mathrm{THP}(m-\mathrm{Pyr})_{2}{ }^{b, d}$ & $354 / 130$ & $376 / 160$ & $519 / 60.0$ & & & $739 / 130.0$ \\
\hline 4 & $\mathrm{H}_{2} \mathrm{P}(p \wedge \mathrm{Pyr})_{2}{ }^{e}$ & $416 / 460$ & & $512 / 19.9$ & $546 / 8.4$ & $588 / 5.6$ & $646 / 4.5$ \\
\hline 5 & $(\mathrm{ZnOEChl})_{2}{ }^{b}$ & $400 / 185$ & $415 / 234$ & & $510 / 10.9$ & $623 / 106.5$ & $633 / 53.0$ \\
\hline 6 & $(\mathrm{ZnOEP})_{2}{ }^{c}$ & $396 / 331$ & $\sim 408 / 216$ & & $556 / 19.2$ & $583 / 12.5$ & $603 / 11.3$ \\
\hline 7 & $(\mathrm{ZnOEP})_{2} \mathrm{Ph}^{b}$ & $407 / 369$ & $418 / 505$ & & $540 / 37.4$ & $574 / 32.2$ & \\
\hline 8 & $(\mathrm{ZnHTPP})_{2}^{b}$ & $416 / 564$ & $427 / 682$ & & $547 / 50.8$ & $587 / 14.9$ & \\
\hline 9 & $(\mathrm{ZnOEChl})_{2} \cdot 2 \mathrm{Pyr}^{f}$ & $415 / 504$ & $426 / 356$ & & $523 / 5$ & $629 / 46$ & $\sim 636 / 40$ \\
\hline 10 & $(\mathrm{ZnOEP})_{2} \cdot 2 \mathrm{Pyr}^{f}$ & $425 / 370$ & $438 / 336$ & $524 / 8$ & $560 / 40$ & $599 / 13$ & \\
\hline 11 & $(\mathrm{ZnOEP})_{2} \mathrm{Ph} \cdot 2 \mathrm{Pyr} \mathrm{r}^{f}$ & $420 / 300$ & $431 / 390$ & & $553 / 35$ & $\sim 584 / 15$ & \\
\hline 12 & $(\mathrm{ZnHTPP})_{2} \cdot 2 \mathrm{Pyr} f, g$ & $426 / 597$ & $436 / 675$ & & $562 / 42$ & $603 / 24$ & \\
\hline 13 & $(\mathrm{ZnHTPP})_{2} \cdot \mathrm{H}_{2} \mathrm{P}(m-\mathrm{Pyr})_{2}^{f}$ & $417 / 670$ & $437 / 600$ & $515 / 26$ & $562 / 38$ & $602 / 22$ & $654 / 4$ \\
\hline 14 & $(\mathrm{ZnHTPP})_{2} \cdot \mathrm{H}_{2} \mathrm{Chl}(m-\mathrm{Pyr})_{2}{ }^{f}$ & $424 / 520$ & $437 / 670$ & $518 / 22$ & $516 / 42$ & $604 / 26$ & $659 / 35$ \\
\hline 15 & $(\mathrm{ZnHTPP})_{2} \cdot \mathrm{H}_{2} \mathrm{THP}(m-\mathrm{Pyr})_{2}{ }^{f}$ & $\begin{array}{l}427 / 600 \\
377 / 150 \\
359 / 140\end{array}$ & $437 / 690$ & $523 / 42$ & $562 / 34$ & $603 / 20$ & $\begin{array}{l}751 / 84 \\
\text { sh, } 740 / 47\end{array}$ \\
\hline 16 & $(\mathrm{ZnHTPP})_{2} \cdot \mathrm{H}_{2} \mathrm{P}(p \wedge \mathrm{Pyr})_{2}^{f}$ & $\begin{array}{l}427 / 734 \\
416 / 620\end{array}$ & $437 / 520$ & $513 / 27$ & $562 / 40$ & $603 / 26$ & $646 / 3$ \\
\hline 17 & $(\mathrm{ZnOEP})_{2} \mathrm{Ph} \cdot \mathrm{H}_{2} \mathrm{P}(m-\mathrm{Pyr})_{2}{ }^{f}$ & $418 / 530$ & $433 / 320$ & $513 / 25$ & $552 / 37$ & $588 / 18$ & $651 / 4$ \\
\hline
\end{tabular}

${ }^{a}$ Decimal extinction coefficients measured in toluene. ${ }^{b}$ Decimal extinction coefficients measured in benzene. ${ }^{c}$ Decimal extinction coefficients measured in chloroform. ${ }^{d}$ Extinction values assumed to be equal to those of the corresponding tetraphenyl-substituted free bases measured in ref 18. ${ }^{e}$ Extinction values assumed to be equal to those of $\mathrm{H}_{2} \mathrm{P}(m \text {-Pyr })_{2} .{ }^{f}$ Extinction coefficients calculated using absorption of the dimer as a reference. $(\mathrm{Pyr}=$ pyridine $) .{ }^{g}$ Mixture $\mathrm{MCH}+10 \% \mathrm{DCM}$ used as a solvent. ${ }^{h}$ An average total error of the extinction values is $15 \%$.

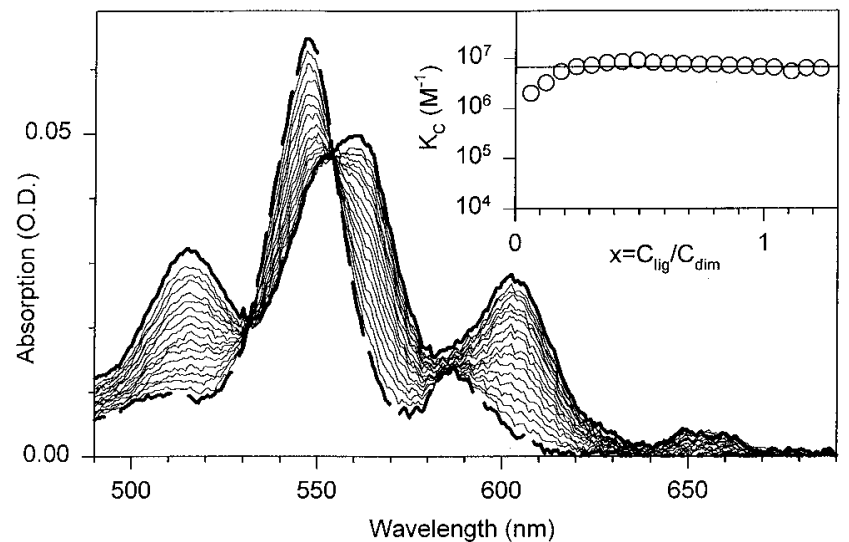

Figure 2. Titration of $(\mathrm{ZnHTPP})_{2}$ with $\mathrm{H}_{2} \mathrm{P}(m-\mathrm{Pyr})_{2}$ in $\mathrm{MCH}$ followed by absorption. The dashed and bold solid lines show the initial and final spectra of the titration procedure, respectively. The inset presents experimental values of the complexation constant, $K_{\mathrm{C}}$ (circles), via the ratio of free base and dimer concentrations, $x$, as well as a calculated average (solid line).

from 604 to $620 \mathrm{~nm}$, where mostly the dimer subunit in the $(\mathrm{ZnHTPP})_{2} \cdot \mathrm{H}_{2} \mathrm{P}(m-\mathrm{Pyr})_{2}$ complex absorbs. $D$ and $D_{\max }$ have been corrected for the underlying absorption of the free dimer and the ligand. Fluorescence intensity was integrated over the range of approximately $10 \mathrm{~nm}$ at the blue side of the $0-0$ band of the uncomplexed dimer. Such a choice of the integration ranges minimizes an error in the calculation of $\beta$. In all cases the spectra were integrated numerically using the MS Excel 4.0 software on a PC.

\section{Results}

3.1. Complexation of $\mathbf{Z n}-$ Porphyrin and $\mathbf{Z n}-$ Chlorin Dimers with Pyridine. To identify spectroscopic effects, which are due to the complexation of $\mathrm{Zn}$-porphyrin dimers with the free bases containing suitable pyridyl substituents, we investigated first the effect of pyridine on the dimers of $\mathrm{Zn}-$ porphyrins and $\mathrm{Zn}-$ chlorins.

Spectral changes characteristic for a complex formation of the dimers with pyridine are similar to those reported for pyridinates of $\mathrm{Zn}$ - porphyrins, ${ }^{20}$ and $\mathrm{Zn}$ - porphyrin chemical homo- ${ }^{4}$ and heterodimers. ${ }^{21}$ So, the complexation of (ZnHTPP $)_{2}$ with pyridine results in a red shift of the visible $(\mathrm{Q})$ and Soret absorption bands on the order of $410-560 \mathrm{~cm}^{-1}$ and a pronounced increase of the $\mathrm{Q}(0,0)$ absorption band with respect to the vibronic $\mathrm{Q}(0,1)$ band $\left(A_{0,1} / A_{0,0}=5.1 \rightarrow 1.8\right.$, Table 1$)$. The splitting of the Soret band of the $(\mathrm{ZnHTPP})_{2}$ pyridinate is slightly reduced $\left(620 \mathrm{~cm}^{-1} \rightarrow 540 \mathrm{~cm}^{-1}\right)$ with respect to the uncomplexed dimer. The splitting in the symmetric porphyrin dimers was interpreted earlier as a result of the excitonic coupling of the strong B transitions of the dimer subunits. ${ }^{2,9,22}$ A red shift and a change in the Franck-Condon envelope are also observed in the fluorescence spectra.

Absorption and emission spectra of $(\mathrm{ZnHTPP})_{2}$ are very close to those of $(\mathrm{ZnTPP})_{2}$. (ZnHTPP $)_{2}$ differs from $(\mathrm{ZnTPP})_{2}$, used in our earlier studies, ${ }^{8,23}$ by hexyl groups attached to the phenyl rings. (ZnHTPP $)_{2}$ was used for the sake of its better solubility in $\mathrm{MCH}$.

The complexation of $(\mathrm{ZnOEP})_{2} \mathrm{Ph}$ with pyridine also manifests itself in a red shift and changes in Franck-Condon envelopes both in absorption and fluorescence spectra (Figure $3 \mathrm{~b})$. However, one should note some differences in comparison with $(\mathrm{ZnHTPP})_{2}$. The reduction in the value of the splitting of the $(\mathrm{ZnOEP})_{2} \mathrm{Ph}$ Soret band upon complexation is lower (40 $\left.\mathrm{cm}^{-1}\right)$ with respect to $(\mathrm{ZnHTPP})_{2}\left(80 \mathrm{~cm}^{-1}\right)$, but the corresponding shift of the Soret band is higher $\left(720-760 \mathrm{~cm}^{-1}\right)$. Additionally, the $\mathrm{Q}(0,0)$ and $\mathrm{Q}(0,1)$ bands of $(\mathrm{ZnOEP})_{2} \mathrm{Ph}$ are of the same intensity, while for $(\mathrm{ZnHTPP})_{2}$ the $\mathrm{Q}(0,0)$ band is much weaker (by a factor of 5.1) than the $\mathrm{Q}(0,1)$ band. The changes of the Franck-Condon envelope upon complexation are also different. In $(\mathrm{ZnOEP})_{2} \mathrm{Ph}$ the intensity of the $\mathrm{Q}(0,0)$ band decreases in absorption as well as in emission (by a factor of 2.3). However, the red shift is comparable $\left(270-440 \mathrm{~cm}^{-1}\right)$ to that in (ZnHTPP) $)_{2}\left(410-490 \mathrm{~cm}^{-1}\right)$.

Changing the spacer between the ZnOEP subunits from phenyl to $-\mathrm{CH}_{2}-\mathrm{CH}_{2}-$ leads to pronounced changes in the spectra. Those can be seen from comparison of $(\mathrm{ZnOEP})_{2}$ and $(\mathrm{ZnOEP})_{2} \mathrm{Ph}$ spectra (Figure $\left.3 \mathrm{~b}, \mathrm{c}\right)$. The Soret band of $(\mathrm{ZnOEP})_{2}$ is blue-shifted relative to that of $(\mathrm{ZnOEP})_{2} \mathrm{Ph}$, and the longwave component of the splitting manifests itself as a shoulder only. The value of the splitting in $(\mathrm{ZnOEP})_{2}$ is essentially higher than in $(\mathrm{ZnOEP})_{2} \mathrm{Ph}$ (compare $\Delta E \approx 900 \mathrm{~cm}^{-1}$ for $(\mathrm{ZnOEP})_{2}{ }^{22}$ 


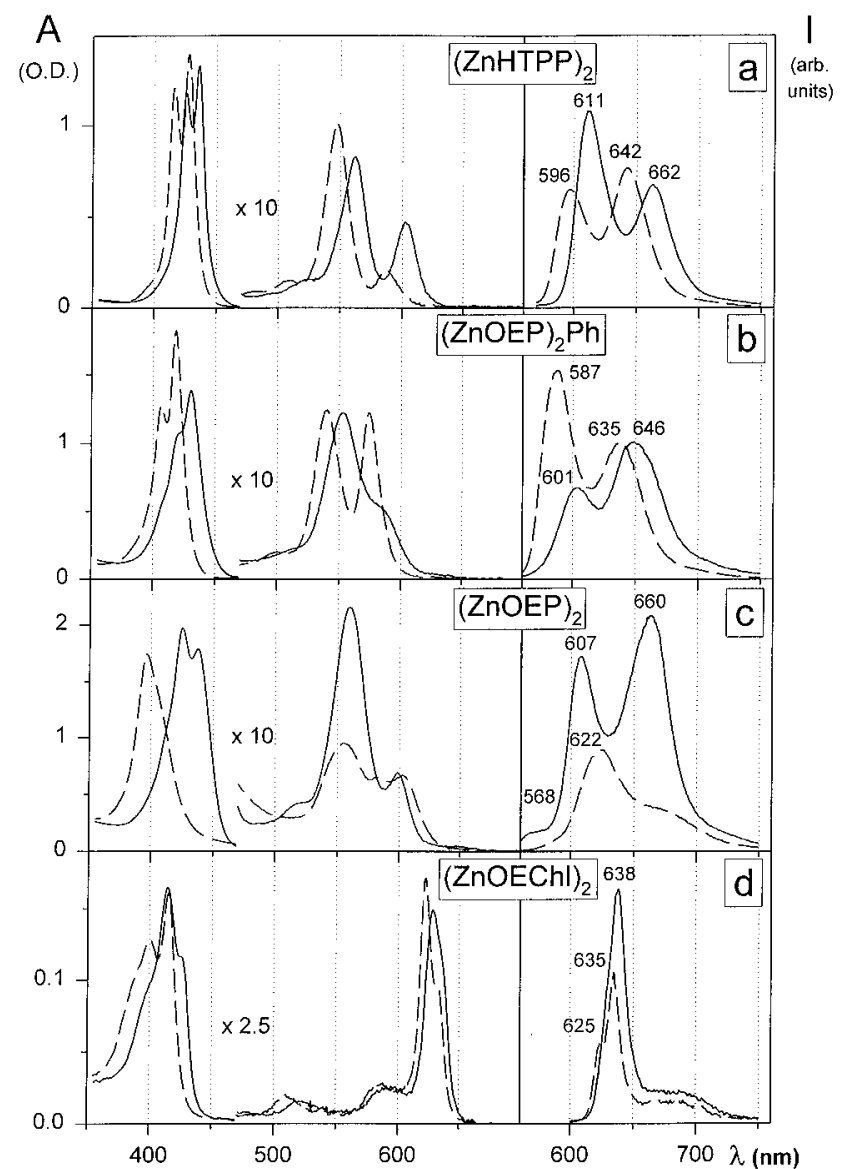

Figure 3. Comparison of pyridinates of the various dimers (absorption $(A)$ and fluorescence $(I)$ spectra $)$. Dimers $\left((\mathrm{ZnHTPP})_{2}(\mathrm{a}),(\mathrm{ZnOEP})_{2} \mathrm{Ph}\right.$ (b), $\left.(\mathrm{ZnOEP})_{2}(\mathrm{c}),(\mathrm{ZnOEChl})_{2}(\mathrm{~d})\right)$ (dashed lines) and their complexes with pyridine (solid lines) in $\mathrm{MCH}$ at room tempeature. Concentration of the dimer $C_{\mathrm{d} 0}=2.0 \times 10^{-6} \mathrm{M}(\mathrm{a}), 3.3 \times 10^{-6} \mathrm{M}(\mathrm{b}), 2.8 \times 10^{-6}$ $\mathrm{M}(\mathrm{c}), 1.3 \times 10^{-6} \mathrm{M}(\mathrm{d})$; excitation of the fluorescence at $\lambda_{\mathrm{ex}}=555$ nm (a) $547 \mathrm{~nm}$ (b), $541 \mathrm{~nm}$ (c) $593 \mathrm{~nm}$ (d); molar ratio of pyridine to the dimer $C_{\text {pyridine }} / C_{\text {dimer }}=7.6 \times 10^{2}(\mathrm{a}), 6.4 \times 10^{2}(\mathrm{~b}), 6.6 \times 10^{3}(\mathrm{c})$, and $1.8 \times 10^{3}(\mathrm{~d})$.

and $\Delta E=650 \mathrm{~cm}^{-1}$ for $\left.(\mathrm{ZnOEP})_{2} \mathrm{Ph}\right)$. The $\mathrm{Q}(0,1)$ absorption band of uncomplexed $(\mathrm{ZnOEP})_{2}$ is in the same wavelength region as that of $(\mathrm{ZnOEP})_{2} \mathrm{Ph}$ pyridinate. The $\mathrm{Q}(0,0)$ absorption band shows a clearly resolved splitting of $570 \mathrm{~cm}^{-1}$ caused by breakdown of the metalloporphin-like degeneracy of the $\mathrm{Q}(0,0)$ transition, as in the case of mono-meso-methyl substitution. ${ }^{15}$ Upon complexation the Soret band exhibits a very large red shift $\left(\sim 1700 \mathrm{~cm}^{-1}\right)$ and a clearly resolved but reduced $(700$ $\left.\mathrm{cm}^{-1}\right)$ splitting. In absorption the $\mathrm{Q}(0,1)$ band is red-shifted by only $130 \mathrm{~cm}^{-1}$, while a blue (!) shift $\left(400 \mathrm{~cm}^{-1}\right.$ in emission and $110 \mathrm{~cm}^{-1}$ in absorption) is observed for the $\mathrm{Q}(0,0)$ bands. Moreover, upon complexation the splitting of the longest wavelength transition is not observed anymore in absorption, but it is well seen in emission $\left(\Delta E=1130 \mathrm{~cm}^{-1}\right.$, Figure 3c). In contrast to $(\mathrm{ZnHTPP})_{2}$ the intensity ratio of $\mathrm{Q}(0,0)$ and $\mathrm{Q}(0,1)$ bands in fluorescence is in favor of the $\mathrm{Q}(0,0)$ band in $(\mathrm{ZnOEP})_{2}$ $(I[\mathrm{Q}(0,0)] / I[\mathrm{Q}(0,1)] \approx 2.4)$. Upon complexation, this ratio is almost reversed $(I[\mathrm{Q}(0,0)] / I[\mathrm{Q}(0,1)] \approx 0.8)$. The same tendency of relative growth of the $\mathrm{Q}(0,1)$ band is observed in the absorption spectra $\left.\left(A_{0,0} / A_{0,1}\right) \approx 0.7 \rightarrow 0.3\right)$. It is noteworthy that in contrast to $(\mathrm{ZnHTPP})_{2}$ and $(\mathrm{ZnOEP})_{2} \mathrm{Ph}$ pyridinates the total emittance and absorbance of the $(\mathrm{ZnOEP})_{2}$ pyridinate are much higher than those of the uncomplexed dimer.

The spectra of $(\mathrm{ZnOEChl})_{2}$ and its complex with pyridine are presented in Figure 3d. As compared to the above mentioned dimers, the fluorescence and absorption origins are clearly red-shifted $\left(200-1100 \mathrm{~cm}^{-1}\right)$. Compared to the por- phyrin systems, the $\mathrm{Q}(0,0)$ absorption band is almost as strong as the Soret band (see Table 1) and split by $\Delta E=280 \mathrm{~cm}^{-1}$. Both the Soret band and the $\mathrm{Q}(0,0)$ absorption band are redshifted (620-900 $\mathrm{cm}^{-1}$ and $80-180 \mathrm{~cm}^{-1}$, respectively) upon complexation with pyridine. The Soret band changes its shape drastically upon complexation, while for the $\mathrm{Q}(0,0)$ band only the long-wavelength shoulder is smeared out. The fluorescence spectrum is dominated by the $\mathrm{Q}(0,0)$ emission band, which (as in absorption) is split by $250 \mathrm{~cm}^{-1}$. Upon complexation with pyridine, this splitting is not clearly seen any more in the largely broadened line which shifts slightly $\left(\sim 200 \mathrm{~cm}^{-1}\right)$ to the red. Assuming that the Soret band splitting is due to dipole-dipole coupling of the transition moments of porphyrin subunits (exciton splitting), one would expect that a similar splitting in the $\mathrm{Q}(0,0)$ band in the case that $\mathrm{Q}$ transitions become as strong as Soret band transitions, which is obviously the case for $(\mathrm{ZnOEChl})_{2}$. In a certain sense, the existence of the splitting only for this compound supports strongly the concept of exciton splitting in porphyrin dimers. The appearance of the splitting (broadening) in fluorescence might be due to thermal activation, which has, however, not yet been checked experimentally.

For the dimers (ZnHTPP) $)_{2}$ and $(\mathrm{ZnOEP})_{2} \mathrm{Ph}$ having a phenyl spacer the spectral changes occur up to pyridine concentrations of approximately $1 \times 10^{-3} \mathrm{M}$, whereas the dimer concentration ranged from $1 \times 10^{-6}$ to $3 \times 10^{-6} \mathrm{M}$. This implies equilibrium constants in the range $K_{\mathrm{C}} \approx 10^{4} \mathrm{M}^{-1}$ for the pyridinates of the dimers. This fact is in good agreement with the equilibrium constants for the complexes of ZnTPP with pyridine $\left(K_{\mathrm{C}}=(6.2\right.$ $\pm 0.6) \times 10^{3} \mathrm{M}^{-1}$ at $\left.293 \mathrm{~K}^{20}\right)$, various nitrogen-containing ligands $\left(K_{\mathrm{C}}=(1-5) \times 10^{4} \mathrm{M}^{-1}\right.$ at $\left.297 \mathrm{~K}^{4}\right)$, and those found for complexes of $\mathrm{Zn}_{2}$-gable porphyrin with 1-methylimidazole and $\gamma$-picoline $\left(K_{\mathrm{C}}=(5-9) \times 10^{4} \mathrm{M}^{-1}\right.$ and $K_{\mathrm{C}}=(1.4-1.6) \times$ $10^{4} \mathrm{M}^{-1}$, respectively $\left.{ }^{4}\right)$. In contrast, for the dimers $(\mathrm{ZnOEP})_{2}$ and $(\mathrm{ZnOEChl})_{2}$ with the $-\mathrm{CH}_{2}-\mathrm{CH}_{2}-$ spacer the corresponding concentration of pyridine up to which changes in the spectra occur is higher by a factor of 10 and 2, respectively, at dimer concentrations of the same order of magnitude as before (see caption to Figure 3). From this follows that the ratios of the corresponding complexation constants are $K_{\mathrm{C}}\left[(\mathrm{ZnOEP})_{2}\right] /$ $K_{\mathrm{C}}\left[(\mathrm{ZnOEP})_{2} \mathrm{Ph}\right] \approx 1 / 10$ and $K_{\mathrm{C}}\left[(\mathrm{ZnOEChl})_{2}\right] / K_{\mathrm{C}}\left[(\mathrm{ZnOEP})_{2^{-}}\right.$ $\mathrm{Ph}] \approx 1 / 2$.

3.2. Complexation of the Dimers with $\mathrm{H}_{2} \mathbf{P}(\boldsymbol{m}-\mathbf{P y r})_{2}$. The visible part of the absorption spectra of $(\mathrm{ZnHTPP})_{2}$ complexed with $\mathrm{H}_{2} \mathrm{P}(m-\mathrm{Pyr})_{2}$ (Figure $\left.4 \mathrm{a}\right)$ is almost the same as upon its complexation with pyridine (Figure $3 \mathrm{a}$ ), when neglecting the additional underlying absorption of the free base (compare the corresponding extinction coefficients from Table 1). This clearly shows that both monomeric subunits of the dimer are coordinated by the pyridyl substituents of the free base. Hereinafter we refer to the complexes formed as triads of macrocycles. Qualitatively the triads behave very similar to the $(\mathrm{ZnTPP})_{2} \cdot \mathrm{H}_{2} \mathrm{P}(m-\mathrm{Pyr})_{2}$ complex, ${ }^{8}$ showing that the additional hexyl groups do not affect the complex formation. The complexation constant $\left(K_{\mathrm{C}}\right)$ was found to be $(6.5 \pm 0.7) \times 10^{6}$ $\mathrm{M}^{-1}$.

The fluorescence of $(\mathrm{ZnHTPP})_{2}$ within the triad is quenched and shifted to the red. The $\mathrm{H}_{2} \mathrm{P}(m \text {-Pyr })_{2}$ fluorescence is also red-shifted $\left(140 \mathrm{~cm}^{-1}\right)$ and increased in intensity (factor of 3.5) (Figures $4 \mathrm{a}$ and $5 \mathrm{~b}$ ) relative to the solution containing the same concentration of free base without the dimer. The fluorescence excitation spectrum of $(\mathrm{ZnHTPP})_{2} \cdot \mathrm{H}_{2} \mathrm{P}(m \text {-Pyr })_{2}$, measured at $\lambda_{\text {reg }}=719 \mathrm{~nm}$, where the free base fluorescence dominates, is very close to the absorption spectrum of the complex, i.e. to a superposition of the bands of the complexed dimer and the free base. 


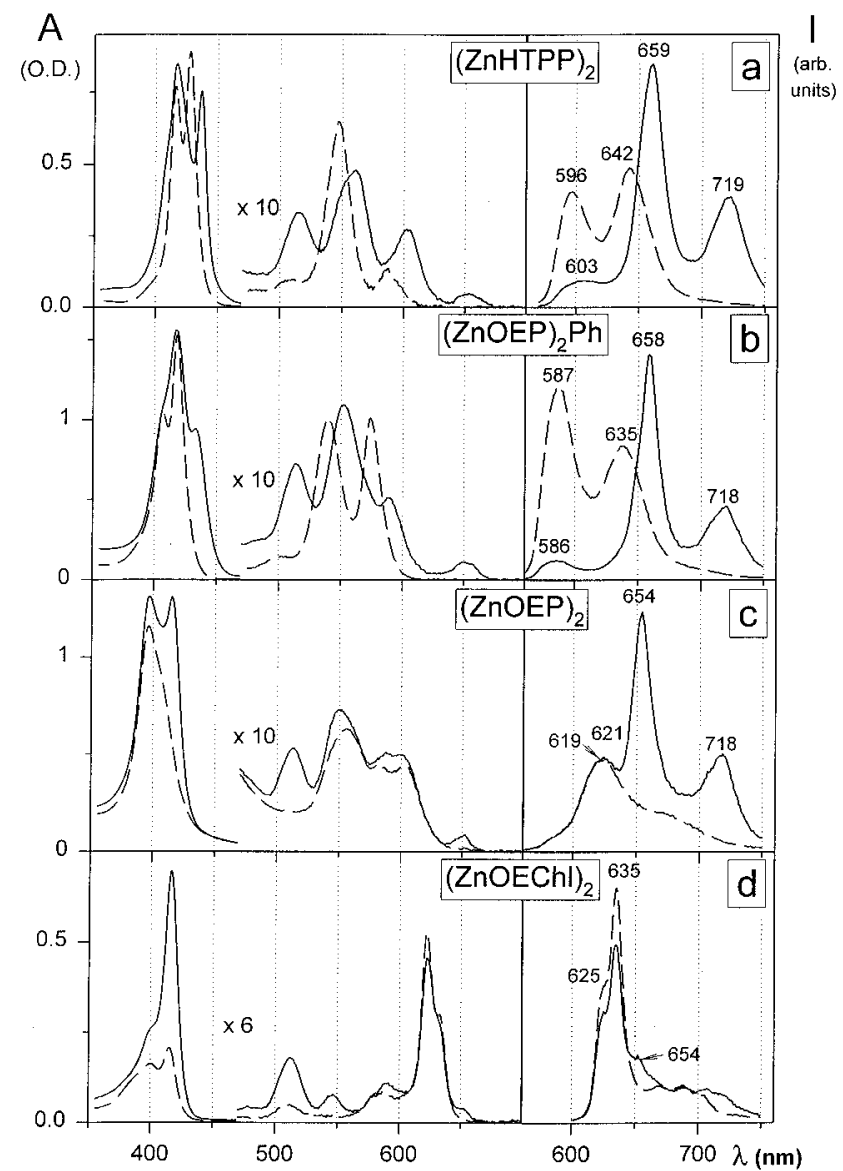

Figure 4. Comparison of the complexes of various dimers with $\mathrm{H}_{2} \mathrm{P}$ $(m \text {-Pyr })_{2}$ (absorption $(A)$ and fluorescence $(I)$ spectra). Dimers (ZnHT$\mathrm{PP})_{2}(\mathrm{a}),(\mathrm{ZnOEP})_{2} \mathrm{Ph}(\mathrm{b}),(\mathrm{ZnOEP})_{2}(\mathrm{c}),(\mathrm{ZnOEChl})_{2}$ (d) (dashed lines) and their complexes with $\mathrm{H}_{2} \mathrm{P}(m \text {-Pyr })_{2}$ (solid lines) in $\mathrm{MCH}$ at room temperature. $C_{\mathrm{d} 0}=1.3 \times 10^{-6} \mathrm{M}(\mathrm{a}), 2.7 \times 10^{-6} \mathrm{M}(\mathrm{b}), 1.8 \times 10^{-6}$ $\mathrm{M}(\mathrm{c}), 8.3 \times 10^{-7} \mathrm{M}(\mathrm{d}) ; \lambda_{\mathrm{ex}}=555 \mathrm{~nm}$ (a), $545 \mathrm{~nm}$ (b), $545 \mathrm{~nm}$ (c), $575 \mathrm{~nm}(\mathrm{~d}) ; C_{\text {ligand }} / C_{\text {dimer }}=1.4(\mathrm{a}, \mathrm{d}), 1.3$ (b), 1.0 (c).

$(\mathrm{ZnOEP})_{2} \mathrm{Ph}$ shows changes in the $\mathrm{Q}$ band absorption upon titration with $\mathrm{H}_{2} \mathrm{P}(m-\mathrm{Pyr})_{2}$ (Figure $\left.4 \mathrm{~b}\right)$ similar to those for the titration with pyridine (Figure $3 \mathrm{~b}$ ). The complexation constant $K_{\mathrm{C}}=(5.8 \pm 1.0) \times 10^{6} \mathrm{M}^{-1}$ is approximately the same as that for $(\mathrm{ZnHTPP})_{2}$ (Table 2). ( $\left.\mathrm{ZnOEP}\right)_{2} \mathrm{Ph}$ also exhibits fluorescence quenching upon complexation with $\mathrm{H}_{2} \mathrm{P}(m-\mathrm{Pyr})_{2}$. The remaining fluorescence belongs probably to the uncomplexed dimer. The fluorescence of $\mathrm{H}_{2} \mathrm{P}(m-\mathrm{Pyr})_{2}$ within the complex is also shifted to the red $\left(120 \mathrm{~cm}^{-1}\right)$ and increases by a factor of 3.2 (Figure $4 b$ ).

Changing the spacer between the ZnOEP monomer moieties in the dimer from phenyl to ethyl leads to a substantial weakening of the complexation. Absorption as well as fluorescence spectra of the 1:1 molar mixture of $(\mathrm{ZnOEP})_{2}$ and $\mathrm{H}_{2} \mathrm{P}$ $(m-\mathrm{Pyr})_{2}$ are simply a superposition of the spectra of the individual components within experimental error (Figure 4c). Neither shifts nor intensity changes like in the case of complexation with pyridine have been detected (compare Figures $4 \mathrm{c}$ and $3 \mathrm{c}$ ). From these facts the complexation constant is estimated to be lower than $2 \times 10^{4} \mathrm{M}^{-1}$.

In the case of $(\mathrm{ZnOEChl})_{2}$ we encounter an intermediate situation between $(\mathrm{ZnOEP})_{2} \mathrm{Ph}$ and $(\mathrm{ZnOEP})_{2}$ (Figure $4 \mathrm{~d}$, Table 2 ). The complexation shifts are not pronounced, and in a $1: 1$ molar mixture of $(\mathrm{ZnOEChl})_{2}+\mathrm{H}_{2} \mathrm{P}(m-\mathrm{Pyr})_{2}$ the quenching is low $(Q=0.25)$. The complexation constant in this case is estimated to be $6 \times 10^{5} \mathrm{M}^{-1}$ assuming that the dimer fluorescence is quenched completely in the complex.

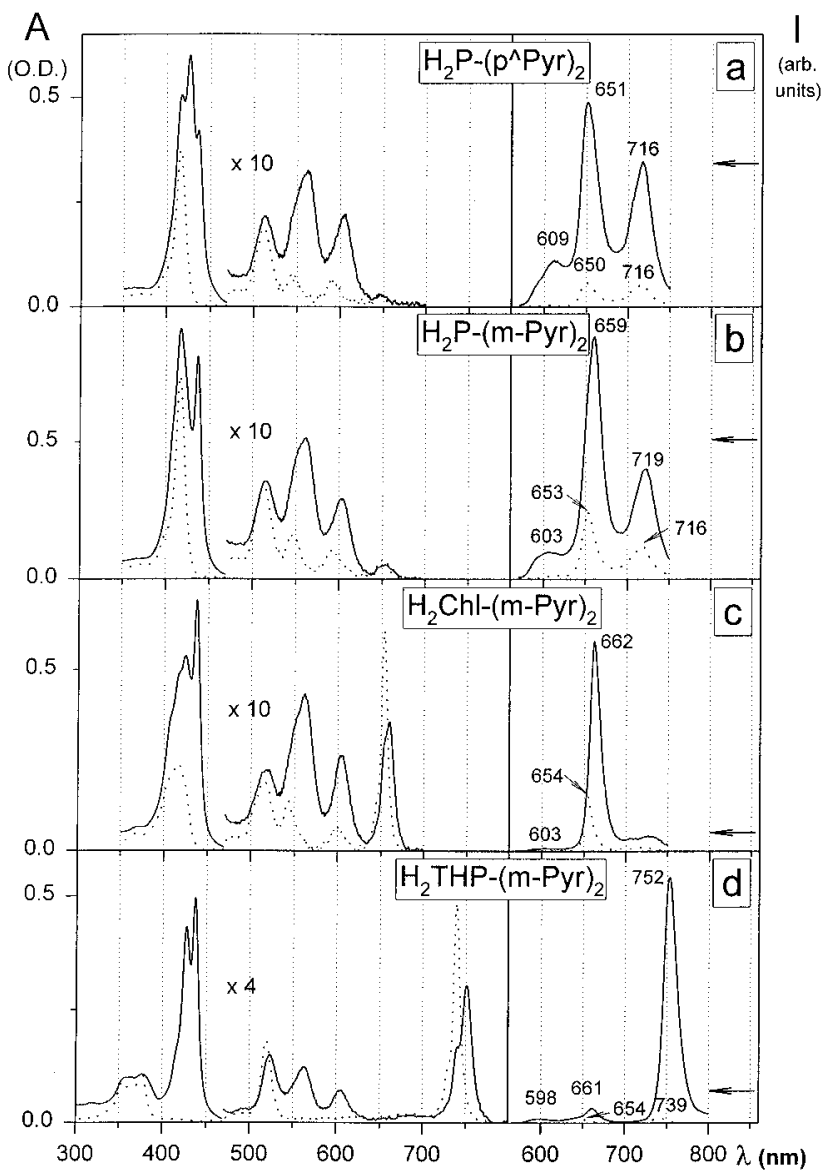

Figure 5. Comparison of complexes of $(\mathrm{ZnHTPP})_{2}$ with the various dipyridyl-substituted free bases (absorption (A) and fluorescence (I) spectra). Complexes of (ZnHTPP $)_{2}$ with the dipyridyl-substituted free bases $\left(\mathrm{H}_{2} \mathrm{P}(p \wedge \mathrm{Pyr})_{2}\right.$ (a), $\mathrm{H}_{2} \mathrm{P}(m-\mathrm{Pyr})_{2}$ (b), $\mathrm{H}_{2} \mathrm{Chl}(m \text {-Pyr })_{2}$ (c), $\mathrm{H}_{2} \mathrm{THP}-$ $\left.(m \text {-Pyr })_{2}(\mathrm{~d})\right)$ (solid lines) and the free bases (dotted lines) in $\mathrm{MCH}$ at room temperature. Intensity of the fluorescence of the initial dimer solution is shown by arrows. $\lambda_{\mathrm{ex}}=555 \mathrm{~nm}$. $C_{\mathrm{d} 0}=1.0 \times 10^{-6} \mathrm{M}(\mathrm{a})$, $1.3 \times 10^{-6} \mathrm{M}(\mathrm{b}), 7.7 \times 10^{-7} \mathrm{M}(\mathrm{c}), 8.3 \times 10^{-7} \mathrm{M}(\mathrm{d}) ; C_{\text {ligand }} / C_{\text {dimer }}=$ 1.0 (a), 1.4 (b), 1.5 (c), 1.3 (d). Concentration of the free bases $C_{\mathrm{L}}=$ $1.0 \times 10^{-6} \mathrm{M}$ (a), $1.8 \times 10^{-6} \mathrm{M}$ (b), $1.1 \times 10^{-6} \mathrm{M}$ (c), $1.1 \times 10^{-7} \mathrm{M}$ (d).

TABLE 2: Structural Parameters and Complexation Constants $\left(K_{\mathrm{C}}\right)$ of the Triads ${ }^{a}$

\begin{tabular}{lllc}
\hline \multicolumn{1}{c}{ complex } & \multicolumn{1}{c}{$d, \AA$} & $l, \AA$ & $K_{\mathbf{C}}, 10^{6} \mathrm{M}^{-1}$ \\
\hline$(\mathrm{ZnHTPP})_{2} \cdot \mathrm{H}_{2} \mathrm{P}(m-\mathrm{Pyr})_{2}$ & 12.6 & 15.1 & $6.5 \pm 0.7$ \\
$(\mathrm{ZnHTPP})_{2} \cdot \mathrm{H}_{2} \mathrm{Chl}(m-\mathrm{Pyr})_{2}$ & 12.6 & 14.4 & $9.0 \pm 0.9$ \\
$(\mathrm{ZnHTPP})_{2} \cdot \mathrm{H}_{2} \mathrm{THP}(m-\mathrm{Pyr})_{2}$ & 12.6 & 14.2 & $50 \pm 7$ \\
$(\mathrm{ZnHTPP})_{2} \cdot \mathrm{H}_{2} \mathrm{P}(\mathrm{m} \wedge \mathrm{Pyr})_{2}$ & 12.6 & 10.0 & $5.0 \pm 3.5$ \\
$(\mathrm{ZnHTPP})_{2} \cdot \mathrm{H}_{2} \mathrm{P}(p \wedge \mathrm{Pyr})_{2}$ & 12.6 & 12.2 & $24 \pm 10$ \\
$(\mathrm{ZnHTPP})_{2} \cdot \mathrm{H}_{2} \mathrm{P}(p-\mathrm{Pyr})_{2}$ & 12.6 & 17.6 & $<0.01^{b}$ \\
$(\mathrm{ZnOEP})_{2} \mathrm{Ph} \cdot \mathrm{H}_{2} \mathrm{P}(m-\mathrm{Pyr})_{2}$ & 12.6 & 15.1 & $5.8 \pm 1.0$ \\
$(\mathrm{ZnOEP})_{2} \cdot \mathrm{H}_{2} \mathrm{P}(m-\mathrm{Pyr})_{2}$ & $5.6-10.6$ & 15.1 & $<0.01^{b}$ \\
$(\mathrm{ZnOEChl})_{2} \cdot \mathrm{H}_{2} \mathrm{P}(m-\mathrm{Pyr})_{2}$ & $4.8-10.8$ & 15.1 & $\sim 0.6$
\end{tabular}

${ }^{a}$ The distances $l$ and $d$ (for definition see Figure 1) have been obtained as a result of computer-aided structure simulation. $K_{\mathrm{C}}$ have been determined in methylcyclohexane at $298 \mathrm{~K} .{ }^{b}$ Calculated from $\beta$ $>0.9 x=5$ (up to $x=5$ no spectral changes due to the complexation are observed; that is, they are within $10 \%$ experimental error in OD or $\left.I_{\mathrm{fl}}\right) . \quad x$ is restricted to $\sim 5$ by low solubility of the ligand and its absorption in the region of OD integration (see section 2).

3.3. Complexation of (ZnHTPP $)_{2}$ with Various DipyridylContaining Ligands. As mentioned above, $(\mathrm{ZnHTPP})_{2}$ and $\mathrm{H}_{2} \mathrm{P}(m \text {-Pyr })_{2}$ form complexes (Figures $4 \mathrm{a}$ and $5 \mathrm{~b}$ and Table 2 ). When $\mathrm{H}_{2} \mathrm{Chl}(m-\mathrm{Pyr})_{2}$ is used instead of $\mathrm{H}_{2} \mathrm{P}(m-\mathrm{Pyr})_{2}$, a similar behavior of the dimer absorption in the visible region is observed (Figure 5c), which indicates also a complex formation in this 

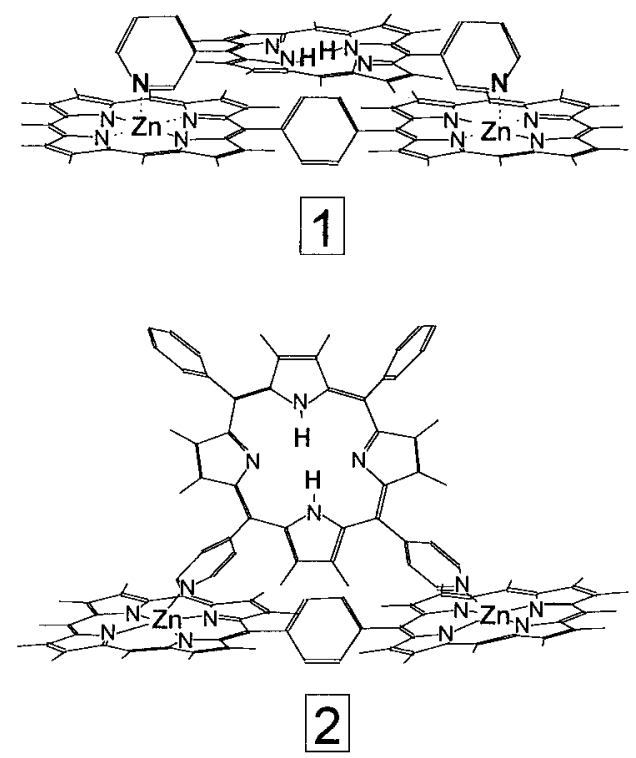

Figure 6. Schematic structures of the complexes formed by the free bases of the $(m-\mathrm{Pyr})_{2}$ type (1) and $\mathrm{H}_{2} \mathrm{P}(p \wedge \mathrm{Pyr})_{2}$ (2) with $(\mathrm{ZnHTPP})_{2}$.

case $\left(K_{\mathrm{C}}=(9 \pm 0.9) \times 10^{6} \mathrm{M}^{-1}\right)$. Upon complexation a red shift of the intense $\mathrm{Q}(0,0)$ absorption band of $\mathrm{H}_{2} \mathrm{Chl}(m-\mathrm{Pyr})_{2}$ $\left(140 \mathrm{~cm}^{-1}\right)$ can be observed clearly. The fluorescence spectrum of the complex (Figure 5c) exhibits a pronounced quenching of the (ZnHTPP $)_{2}$ emission. The $\mathrm{H}_{2} \mathrm{Chl}(m-\mathrm{Pyr})_{2}$ bands also are red-shifted $\left(180 \mathrm{~cm}^{-1}\right)$ and increase in intensity by a factor of 3.8 .

Formation of the $(\mathrm{ZnHTPP})_{2} \cdot \mathrm{H}_{2} \mathrm{THP}(m-\mathrm{Pyr})_{2}$ complexes can be revealed by the typical red shifts of the dimer absorption bands (450-620 $\mathrm{cm}^{-1}$; Figure $5 \mathrm{~d}$ ). The changes of the dimer spectrum upon complexation can be observed most clearly here, since the dimer and the tetrahydroporphyrin ligand show almost no overlap of their absorption bands. The complexation constant for this system $\left(K_{\mathrm{C}}=(5.0 \pm 0.7) \times 10^{7} \mathrm{M}^{-1}\right)$ turned out to be approximately 1 order of magnitude higher than that for the above mentioned systems (Table 2). Quenching of (ZnHTPP) fluorescence as well as the increase (by factor of 39) and the red shift of $\mathrm{H}_{2} \mathrm{THP}(m-\mathrm{Pyr})_{2}$ fluorescence $\left(230 \mathrm{~cm}^{-1}\right)$ can also be observed in this case (Figure $5 \mathrm{~d}$ ). We attribute the remaining dimer fluorescence to the uncomplexed dimer. (An additional band peaked near $660 \mathrm{~nm}$ is due to fluorescence of an unavoidable chlorin impurity (ca. 5\%) in the tetrahydroporphyrin sample used.)

In $\mathrm{H}_{2} \mathrm{P}(p \wedge \mathrm{Pyr})_{2}$ the nitrogen atoms being in the para-position of the pyridyl rings are separated by a distance of $l=12.2 \AA$ (see Figures 1 and 6), which is by 2.0-2.9 $\AA$ less than for the di- $m$-pyridyl-substituted free bases. Another feature of the compound is that the lone pair electron orbitals of nitrogen atoms, which participate in the coordination of the $\mathrm{Zn}$ ions of the dimers, form an angle of $90^{\circ}$ with each other. A strong complexation of $(\mathrm{ZnHTPP})_{2}$ with $\mathrm{H}_{2} \mathrm{P}(p \wedge \mathrm{Pyr})_{2}\left(K_{\mathrm{C}}=(2.4 \pm\right.$ 1) $\times 10^{7} \mathrm{M}^{-1}$; Table 2) was observed (Figure 5a). The intensity distribution in the Soret band of the complex differs from those observed for complexes of (ZnHTPP $)_{2}$ with pyridine or di- $m$ pyridyl-containing ligands (compare Figure 5a and for example, Figure 5d). Fluorescence of the dimer within the complex is clearly red-shifted $\left(360 \mathrm{~cm}^{-1}\right)$ but quenched to a lesser extent ( $Q=0.77$ taking into account the intensity redistribution upon titration) as compared to the di- $m$-pyridyl-substituted extraligands. The $\mathrm{H}_{2} \mathrm{P}(p \wedge \mathrm{Pyr})_{2}$ fluorescence shows almost no red shift $\left(20 \mathrm{~cm}^{-1}\right)$ but increases in intensity (8.5) with respect to the uncomplexed $\mathrm{H}_{2} \mathrm{P}(p \wedge \mathrm{Pyr})_{2}$.

No noticeable complex formation was observed upon titration of $(\mathrm{ZnHTPP})_{2}$ solution with $\mathrm{H}_{2} \mathrm{P}(p-\mathrm{Pyr})_{2}$ at room temperature. In this case both the distance between the nitrogen atoms located in the para-position of the pyridyl rings $(l=17.6 \AA$ compared to $d=12.6 \AA$ in the dimer subunits) and the geometry, where lone pair orbitals of the nitrogens point to opposite directions, prevent 2-fold coordination of (ZnHTPP) $)_{2}$ (Figure 1).

\section{Discussion}

4.1. Formation of the Complexes. The above reported experimental results unambiguously show that $(\mathrm{ZnHTPP})_{2}$ and $(\mathrm{ZnOEP})_{2} \mathrm{Ph}$ form complexes with the dipyridyl-substituted free bases in which both subunits of the dimers interact with the pyridyl-type ligands. A brief glance at the complexation constants obtained for these complexes (Table 2) shows that they are much higher than those for the complexes of $\mathrm{Zn}-$ porphyrins ${ }^{20}$ and their dimers ${ }^{4}$ with pyridine and related ligands (see section 3.1). On the other hand these values are close to those obtained for 2-fold-coordinated complexes of various $\mathrm{Zn}-$ porphyrin dimers with bifunctional ligands $\left(K_{\mathrm{C}}=(6 \pm 5) \times\right.$ $10^{7} \mathrm{M}^{-1}$ or $(5 \pm 3) \times 10^{6} \mathrm{M}^{-1}$ for the complexes of $\mathrm{Zn}_{2}$-gable porphyrins with $N, N^{\prime}$-diimidazolylmethane or $\gamma, \gamma^{\prime}$-dipyridylmethane, respectively $\left.{ }^{4}\right)$ and dipyridyl-substituted porphyrins $\left(K_{\mathrm{C}}=7 \times 10^{7} \mathrm{M}^{-1}\right.$ for $\left.(\mathrm{ZnTPP})_{2} \cdot \mathrm{H}_{2} \mathrm{P}(m-\mathrm{Pyr})_{2}{ }^{8}\right)$. Additionally, these dimers are complexed almost completely when the molar ratio of the dimer and the free base in the mixture is close to 1:1 (Figures 4 and 5). These facts together with the spectral behavior of the mixtures described above lead to the conclusion that the complexes are formed due to 2-fold coordination of $\mathrm{Zn}$ ions of the dimers by nitrogen atoms of the pyridyl substituents of the free bases. Each complex consists of one dimer and one free base forming a triad of the macrocycles.

4.2. Spectral Effects Due to Ligation. To analyze the spectral behavior of the dimers upon complexation with bifunctional pyridyl-containing ligands, the spectra of the dimer pyridinates (Figure2) have been taken as a reference. (Hereinafter, the term "dimer pyridinate" represents a complex of a dimer and two pyridine molecules attached to the individual dimer subunits.)

The analysis of the absorption spectra of the mixtures of $\mathrm{Zn}-$ porphyrin dimers and various free bases (Figures 4 and 5) reveals a similar behavior as compared to their pyridinates (compare Figures 4a,b,d and 5 with Figure 3). Upon complex formation, the visible absorption bands of the dimers $(\mathrm{Q}(0,0)$ and $\mathrm{Q}(0,1))$ are shifted to the red $\left(\Delta v \sim 450 \mathrm{~cm}^{-1}\right)$ with essential intensity redistribution. Analogous effects have been reported for complexes of various $\mathrm{Zn}$-porphyrins as well as their chemical dimers with pyridine and numerous pyridyl-containing molecules. ${ }^{4,5,8.20}$ Both 1- and 2-fold coordination as well as different coordination geometries results in similar spectral effects (compare, for example, Figures 3a, 4a, and 5a). Thus, the red shift and redistribution of relative Q-band intensity can be considered as a characteristic spectral effect caused by coordination of the $\mathrm{Zn}$ ion in porphyrins or their chemical dimers by the nitrogen atom of various ligands. The behavior of $(\mathrm{ZnOEChl})_{2}$ absorption spectra in the visible region upon complexation with pyridine (Figure $3 \mathrm{~d}$ ) allows us to extend this conclusion to chlorin compounds as well.

The Soret bands of the complexes are also shifted to the red (Figures 3-5) with respect to those of the uncomplexed dimers but to a larger extent $\left(600-900 \mathrm{~cm}^{-1}\right)$ than the visible ones. Additionally, the complexation leads to an intensity redistribution and a change in the splitting of the Soret band upon the complex formation. As can be seen from a comparison of the Soret regions of $(\mathrm{ZnHTPP})_{2} \cdot \mathrm{H}_{2} \mathrm{P}(m-\mathrm{Pyr})_{2} / \mathrm{H}_{2} \mathrm{Chl}(m-\mathrm{Pyr})_{2} / \mathrm{H}_{2}-$ $\mathrm{THP}(m \text {-Pyr })_{2}$ (Figure $5 \mathrm{~b}, \mathrm{c}, \mathrm{d}$, respectively) with $(\mathrm{ZnHTPP})_{2} \cdot \mathrm{H}_{2} \mathrm{P}$ - 
$(p \wedge \mathrm{Pyr})_{2}$ (Figure $\left.5 \mathrm{a}\right)$, the intensity redistribution depends essentially on the complex. These effects can be explained making use of the interpretation that the shape of the Soret band of the $\mathrm{Zn}$-porphyrin and $\mathrm{Zn}$-chlorin dimers and its splitting are determined mainly by excitonic coupling and vibronic effects. ${ }^{15}$ This excitonic coupling depends on the mutual position of the interacting dipoles and their strength. ${ }^{24}$ According to the computer-aided simulation of the triad structure, upon complexation of the dimers with the dipyridyl-substituted free bases, their structure might be somewhat distorted (most likely a bend relative to the spacer and a rotation about the long axis). Moreover, the distortion depends on the type of the dipyridyl-containing ligand. These estimations are made for the ground-state conformation. An optical excitation changes most likely the conformation to a certain extent. Thus, it will be difficult to draw quantitative conclusions concerning the conformation of the excited state from the (excitonic) splitting of the Soret band. However, it is quite obvious that different types of 2-fold coordination result in different shapes of the Soret band. In the triads (especially in those containing extraligands of the ( $m$-Pyr $)_{2}$-type) the Soret transitions of the free bases could be involved into the excitonic coupling with those of the dimer subunits. Whether they are really excitonically coupled, cannot be answered without a careful analysis of nearly degenerate or degenerate states in the complexes. This subject, however, is beyond the scope of the present publication. Nevertheless, it is a not yet fully used challenge to exploit the Soret band splitting for a detailed analysis of the structure of the triads and therefore awaits further evaluation.

4.3. Effects of the Spacers on Complexation. Comparing the dimers under investigation by their ability to form complexes with $\mathrm{H}_{2} \mathrm{P}(m-\mathrm{Pyr})_{2}$, a pronounced difference is observed when comparing the dimers linked by different spacers. Complexes of the dimers with a phenyl spacer, $(\mathrm{ZnHTPP})_{2} \cdot \mathrm{H}_{2} \mathrm{P}(m-\mathrm{Pyr})_{2}$ and $(\mathrm{ZnOEP})_{2} \mathrm{Ph} \cdot \mathrm{H}_{2} \mathrm{P}(m-\mathrm{Pyr})_{2}$, are characterized by complexation constants of approximately $6 \times 10^{6} \mathrm{M}^{-1}$. Much lower values were found for the complexes of the ethyl-bridged dimers, $(\mathrm{ZnOEP})_{2} \cdot \mathrm{H}_{2} \mathrm{P}(m-\mathrm{Pyr})_{2}\left(K_{\mathrm{C}}<2 \times 10^{4} \mathrm{M}^{-1}\right)$ and $(\mathrm{ZnOEChl})_{2} \cdot \mathrm{H}_{2} \mathrm{P}(m-\mathrm{Pyr})_{2}\left(K_{\mathrm{C}} \approx 6 \times 10^{5} \mathrm{M}^{-1}\right)$. These differences can be well understood from the different geometry and conformational mobility of dimers with phenyl and $-\mathrm{CH}_{2}-$ $\mathrm{CH}_{2}-$ spacers.

Generally, a complex formation causes changes in the conformational dynamics of the complex components with respect to that of the uncomplexed molecules. An analysis of the conformational behavior of the dimers with different spacers can aid understanding the phenomena observed upon complex formation. So, for (ZnTPP) $)_{2}$ (and for $(\mathrm{ZnHTPP})_{2}$ ) there exist two energetically favored conformations: one with coplanar porphyrin units and one with them tilted at $110^{\circ} .25$ In contrast, in $(\mathrm{ZnOEP})_{2} \mathrm{Ph}$ the ethyl groups restrict the phenyl bridge to a position orthogonal to the porphyrin planes, thus allowing for a coplanar structure only. ${ }^{3}$ Almost equal abilities of (ZnHTPP) and $(\mathrm{ZnOEP})_{2} \mathrm{Ph}$ to form various complexes (Table 2 ) imply that the conformational dynamics of the phenyl-bridged dimers does not play an essential role in their interaction with coordinating agents. On the other hand, the splitting $(\Delta E)$ of the Soret band, which is an indicator of the definite geometry of the dimers, is the same both in, e.g., $(\mathrm{ZnHTPP})_{2} \cdot \mathrm{H}_{2} \mathrm{P}(m$ $\mathrm{Pyr})_{2}$, where the geometry of the 2-fold coordination requires nearly coplanar arrangement of the dimer subunits (Figure 4a, $\Delta E=540 \mathrm{~cm}^{-1}$ ), and in the pyridinate of the dimer (Figure $3 \mathrm{a}, \Delta E=540 \mathrm{~cm}^{-1}$ ). This fact implies that in all complexes under investigation the macrocycles of the dimer subunits are presumably coplanar. Thus, the above mentioned conforma- tional freedom of $(\mathrm{ZnHTPP})_{2}$ is restricted upon ligation, while that of $(\mathrm{ZnOEP})_{2} \mathrm{Ph}$ remains unchanged. Therefore, the described difference in the spectral shifts of the Soret bands of these dimers upon complexation with pyridine may be due to the different change in their conformational dynamics.

In the case of the ethyl-bridged dimers there is much more conformational flexibility. On the basis of ${ }^{1} \mathrm{H}$ NMR data we have shown ${ }^{22}$ that ethane-bis(porphyrin)s with a single $-\mathrm{CH}_{2}-$ $\mathrm{CH}_{2}-$ bond via mesopositions (e.g., $(\mathrm{ZnOEP})_{2}$ ) have a wide set of conformations due to rotation around the spacer. The probability of the fully staggered conformation providing the best conditions for two-point coordination, in which the $-\mathrm{CH}_{2}-$ $\mathrm{CH}_{2}$ - spacer is in an all-trans conformation, is relatively low at $293 \mathrm{~K}$. However, for $(\mathrm{ZnOEChl})_{2}$ the fully staggered conformation is favored since hydrogenated rings of the chlorin subunits of the dimer hinder other conformations. Hence, upon complexation with pyridine, when the coordination sterically hinders all conformations except the fully staggered one, a change of conformational dynamics in $(\mathrm{ZnOEP})_{2}$ should be more essential in comparison with $(\mathrm{ZnOEChl})_{2}$. The difference in behavior of the Soret bands of these dimers upon complexation with pyridine (see section 3.1 and compare parts $c$ and d Figure 3) agrees with this conclusion.

Thus, the favored coplanar arrangement of porphyrin subunits in the phenyl-bridged dimers $(d=12.6 \AA)$ is more suitable for the formation of the 2-fold-coordinated complex with $\mathrm{H}_{2} \mathrm{P}(m-$ $\mathrm{Pyr}_{2}(l=15.1 \AA)$ in comparison with the non-coplanar structure (even in the fully staggered conformation) and $d=10.6 \AA$ in the $-\mathrm{CH}_{2}-\mathrm{CH}_{2}-$ bridged dimers ${ }^{22}$ (see Figures 1 and 6). The lower ability of $(\mathrm{ZnOEP})_{2}$ to form complexes with $\mathrm{H}_{2} \mathrm{P}(m \text {-Pyr })_{2}$ in comparison with that of $(\mathrm{ZnOEChl})_{2}$ can be caused by the higher conformational mobility of the former. Another source of this difference can be found in the higher complexation constants for the formation of $\mathrm{Zn}$-chlorin pyridinates as compared to those of the corresponding $\mathrm{Zn}$-porphyrins $\left(K_{\mathrm{C}}=\right.$ $3.7 \times 10^{3} \mathrm{M}^{-1}$ and $5.2 \times 10^{3} \mathrm{M}^{-1}$ for ZnTPP and ZnTPChl, respectively, in benzene ${ }^{20}$ ).

4.4. Effects of Ligands on Complexation. Let us turn to the effects caused by the various dipyridyl-substituted free bases as complex partners for $(\mathrm{ZnHTPP})_{2}$. Employing $\mathrm{H}_{2} \mathrm{P}(p \wedge \mathrm{Pyr})_{2}$ as a coordinating agent for (ZnHTPP $)_{2}$ suggests an essentially different structure of the 2-fold-coordinated complex with respect to that with $\mathrm{H}_{2} \mathrm{P}(m-\mathrm{Pyr})_{2}$ (see Figure 6). In this case the geometry of the pyridyl substitution $(l=12.2 \AA)$ provides better matching for 2-fold coordination with $(\mathrm{ZnHTPP})_{2}(d=$ $12.6 \AA)$ in comparison with that in $\mathrm{H}_{2} \mathrm{P}(m \text {-Pyr })_{2}(l=15.1 \AA)$. Taking into account this difference in the structure of the extraligands, it can be easily explained why the complexation constant for $(\mathrm{ZnHTPP})_{2} \cdot \mathrm{H}_{2} \mathrm{P}(p \wedge \mathrm{Pyr})_{2}$ is about 4 times higher than that for $(\mathrm{ZnHTPP})_{2} \cdot \mathrm{H}_{2} \mathrm{P}(m \text {-Pyr })_{2}$ (Table 2$)$. On the other hand, molecules of the dipyridyl-substituted free bases and the dimers are flexible enough to allow for the 2-fold coordination in both types of triads, which has been shown by use of computer-aided simulation.

Comparing the complexation constants for $\mathrm{H}_{2} \mathrm{P}(m \text {-Pyr })_{2}, \mathrm{H}_{2}-$ $\mathrm{Chl}(m-\mathrm{Pyr})_{2}$, and $\mathrm{H}_{2} \mathrm{THP}(m-\mathrm{Pyr})_{2}$, one finds a certain tendency for increase in complexation constant $\left(K_{\mathrm{C}}=(0.6 \rightarrow 0.9 \rightarrow 5.0)\right.$ $\left.\times 10^{7} \mathrm{M}^{-1}\right)$ over this series. This difference can be explained in terms of both the different geometry of the free bases and their different electronic structure. So, hydrogenation of the pyrrole ring(s) in the porphyrin macrocycle sterically hinders the adjacent phenyl (or pyridyl rings in the pyridyl-substituted porphyrins) to the position in which their planes are almost perpendicular to the plane of the macrocycle. (In the "usual" geometry of phenyl- (or pyridyl-) substituted porphyrins the 
planes of the substituents are tilted to that of the macrocycle by ca. $60^{\circ}$.) Such a geometry strengthens the complex formation due to a smaller distance between the active sites of substituents $(l=15.1 \rightarrow 14.2 \AA)$ and a proper orientation of the lone pair orbitals of the nitrogen atoms. On the other hand, it is known ${ }^{26}$ that in chlorins (and in tetrahydroporphyrins as well) the electron density on the meso-positions of the methine bridges in the vicinity of the hydrogenated pyrrole ring is higher than in the corresponding porphyrins. Since the pyridyl substituents are attached to the meso-positions, an increase of the "electrondonating ability" of the pyridyl nitrogen and, in turn, its ability to coordinate $\mathrm{Zn}$ ions of the dimer subunit is most likely to occur. Thus, the complexation constant of the complexes under investigation should grow from $\mathrm{H}_{2} \mathrm{P}(m-\mathrm{Pyr})_{2}$ to $\mathrm{H}_{2} \mathrm{Chl}(m-\mathrm{Pyr})_{2}$ and to $\mathrm{H}_{2} \mathrm{THP}(m \text {-Pyr })_{2}$, which agrees with the experimental results. The greater difference of complexation constants $\left(\Delta K_{\mathrm{C}}\right)$ for $\mathrm{H}_{2} \mathrm{P}(m-\mathrm{Pyr})_{2}$ and $\mathrm{H}_{2} \mathrm{Chl}(m-\mathrm{Pyr})_{2}\left(\Delta K_{\mathrm{C}} \sim 4 \times 10^{-6} \mathrm{M}^{-1}\right)$ and for $\mathrm{H}_{2} \mathrm{Chl}(m-\mathrm{Pyr})_{2}$ and $\mathrm{H}_{2} \mathrm{THP}(m-\mathrm{Pyr})_{2}\left(\Delta K_{\mathrm{C}} \sim 40 \times 10^{-6}\right.$ $\left.\mathrm{M}^{-1}\right)$ is most likely due to cooperativity of the two-point interaction.

The essential importance of the geometry of the two-point coordination for the formation of the complexes with the dipyridyl-substituted free bases is additionally highlighted by inspecting the $(\mathrm{ZnHTPP})_{2} \cdot \mathrm{H}_{2} \mathrm{P}(m \wedge \mathrm{Pyr})_{2}$ complex. In this case the distance $l(10.0 \AA)$ is shorter than the $\mathrm{Zn}-\mathrm{Zn}$ distance $d$ of $12.6 \AA$. The complexation constant of $(5.0 \pm 3.5) \times 10^{6} \mathrm{M}^{-1}$ is approximately the same as for the (ZnHTPP $)_{2} \cdot \mathrm{H}_{2} \mathrm{P}(m-\mathrm{Pyr})_{2}$ $\left((6.5 \pm 0.7) \times 10^{6} \mathrm{M}^{-1}\right)$, in which case the distance $l(15.1 \AA)$ is larger than $\boldsymbol{d}$ by approximately the same amount.

Now let us turn to the spectral effects caused by the complex formation in the free bases. In contrast to $(\mathrm{ZnHTPP})_{2} \cdot \mathrm{H}_{2} \mathrm{P}$ $(p \wedge \mathrm{Pyr})_{2}$, where spectra of the free base are not noticeably affected, in the complexes with the $(m-\mathrm{Pyr})_{2}$ type free bases their spectra are shifted to the red (compare curves for the various free bases in Figure 5; Table 1) with respect to the uncomplexed free bases. An analysis of the shifts reveals that there is a certain tendency for increase of the shift over the series $\mathrm{H}_{2} \mathrm{P}(m \text {-Pyr })_{2} \rightarrow \mathrm{H}_{2} \mathrm{Chl}(m \text {-Pyr })_{2} \rightarrow \mathrm{H}_{2} \mathrm{THP}(m \text {-Pyr })_{2}, \Delta v_{\text {abs }}$ $=\sim 40 \rightarrow 140 \rightarrow 220 \mathrm{~cm}^{-1}$ in absorption and $\Delta v_{\mathrm{fl}}=140 \rightarrow$ $180 \rightarrow 230 \mathrm{~cm}^{-1}$ in emission. It is of interest that the behavior of the red shift goes along with the aforementioned increase in the complexation constant. These effects could be explained from the above discussed redistribution of electron density in the macrocycle upon hydrogenation. However, additional data are necessary to confirm this conclusion.

4.5. Energy Transfer in the Complexes. The emission of the mixtures in general consists of the fluorescence bands of the remaining uncomplexed dimer and free base and the bands shifted with respect to them belonging to the dimer and free base within the complex (see Figures 4 and 5). However, the red-shifted emission of the dimer within the complex is quenched and that of the free base is much higher in comparison with the same concentration of uncomplexed molecules under analogous conditions of excitation. The effects leading to the red shift of the fluorescence bands of the dimers within the complexes are the same as have been discussed before for the corresponding absorption bands. ${ }^{21}$ The observed quenching of the dimer fluorescence and the sensibilization of the free base fluorescence are clear evidence for an energy transfer (ET) between them. Such an ET between $\mathrm{Zn}$-porphyrins and the corresponding free bases have been reported for many aggregates and covalently bound heterodimers. 2,3,8,21,27 Certainly, a discussion of ET merely by means of steady-state experiments can be only qualitative. Nevertherless, we would like to point out some aspects which may stimulate time-resolved experiments in the near future.

Let us analyze the fluorescence spectra of the (ZnHTPP) complexes with various free bases in more detail. Taking into account that only the red-shifted emission belongs to the dimer within the complex and the distribution of the fluorescence intensity is similar to that in the complexes of the dimers with pyridine, the fluorescence quenching seems to become more pronounced following the series of triads containing $\mathrm{H}_{2} \mathrm{P}(p \wedge \mathrm{Pyr})_{2}$, $\mathrm{H}_{2} \mathrm{P}(m-\mathrm{Pyr})_{2}, \mathrm{H}_{2} \mathrm{Chl}(m-\mathrm{Pyr})_{2}$, and $\mathrm{H}_{2} \mathrm{THP}(m-\mathrm{Pyr})_{2}$. This triad series is characterized by different values of the gap between the longest wave electronic transition in absorption of the complexed dimer and the fluorescent state of the free bases $(\Delta E$ $\approx 1200,1400,1500$, and $3300 \mathrm{~cm}^{-1}$, respectively) as well as by the different lifetimes $\tau$ of the $S_{1}$ states of the ligands (acceptors) ( $\tau=9.4,9.4,8.4$, and $4.0 \mathrm{~ns}$, respectively, in nondegassed $\mathrm{MCH}$ at $298 \mathrm{~K}^{28}$ ). The fact that the amount of fluorescence quenching goes along with the increase in $\Delta E$ as well as with the decrease in $\tau$ implies that thermally activated back ET (from the free base to the dimer) may play an important role, as has been found for $(\mathrm{ZnTPP})_{2} \cdot \mathrm{H}_{2} \mathrm{P}(m \text {-Pyr })_{2}{ }^{29}$ previously. The rates for the ET from (ZnHTPP $)_{2}$ to the free bases are expected to be at least 1 order of magnitude higher than that of the electronic excitation deactivation in the dimer within the complexes, since in the fluorescence decay of $(\mathrm{ZnTPP})_{2}$ in the (ZnTPP $) \cdot \mathrm{H}_{2} \mathrm{P}(m-\mathrm{Pyr})_{2}$ complex we observed only components which are faster than $\sim 100$ ps. ${ }^{29}$ Time-resolved experiments at different temperatures are in progress to allow for a detailed interpretation of ET processes in the complexes.

\section{Conclusion}

We have shown that triad complexes can be formed from $\mathrm{Zn}$-porphyrin or $\mathrm{Zn}$-chlorin dimers and various dipyridylsubstituted free base units. The coupling between the complex partners is accomplished by the pyridyl groups of the free base acting as axial extra-ligands to the $\mathrm{Zn}$ ions of the dimers. The geometry of the triads can be controlled by merely steric considerations.

Two main factors influence the ability of complex formation measured by the equilibrium constants $K_{\mathrm{C}}$. Firstly, most important is a match of the distance between the $\mathrm{Zn}$ ions of the dimer and that between the coordinating nitrogens, although the flexibility of the molecules allows for complexation even in the case of inexact matching. Secondly, the chemical nature of the free base partner is also important for the complex stability. Selective hydrogenation of the pyrrole rings increases the complex stability. Up to now it is undecided whether this is due to electronic redistribution or changes in the orientation of the pyridyl groups.

These basic principles of complex formation allow for a systematic tailoring of self-aggregated supramolecular complexes, making use of a keyhole principle. We have already extended this working principle to still more complex aggregates like porphyrin pentads. Additionally, combining components with different electron donor-acceptor abilities will open a wide range of functionalized supramolecular units.

Acknowledgment. Financial support by a grant from "Stiftung Volkswagen" (No. I/68 941) is gratefully acknowledged. Some of the experiments have been performed at the Physics Department of the Freie Universität Berlin and have been supported partly by the DFG (SFB 337). We thank Dr. H. Buntkowski (FU Berlin) for measurements of the mass spectra and Dr. E. Borisov (Institute of Physical and Organic Chemistry, Minsk) for measurements of the $200 \mathrm{MHz}$ NMR spectra. 


\section{References and Notes}

(1) Wasielewski, M. R. Chem. Rev. 1992, 92, 435.

(2) Zenkevich, E. I.; Shulga, A. M.; Chernook, A. V.; Gurinovich, G. P.; Sagun, E. I. In Light in Biology and Medicine; Plenum Press: New York and London, 1991; Vol. 2, pp 337-344.

(3) Osuka, A.; Maruyama, K.; Yamazaki, I.; Tamai, N. Chem. Phys. Lett. 1990, 165, 392.

(4) Tabushi, I.; Kugimiya, S.; Kinnaird, M. G.; Sasaki, T. J. Am. Chem. Soc. 1985, 107, 4192 .

(5) Tabushi, I.; Kugimiya, S. J. Am. Chem. Soc. 1986, 108, 6926.

(6) Lehn, J.-M. Angw. Chem., Int. Ed. Engl. 1988, 27, 89.

(7) Schneider, H. J.; Dürr, H. Frontiers in Supramolecular Organic Chemistry and Photochemistry; Verlag Chemie: Weinheim, 1991.

(8) Rempel, U.; von Maltzan, B.; von Borczyskowski, C. J. Lumin. 1992, 53, 175 .

(9) Lindsey, J. S.; Schreiman, I. C.; Hsu, H. C.; Marguerettaz, A. M. J. Org. Chem. 1987, 52, 827.

(10) Badger, G. M.; Jones, R. A.; Laslet, R. L. Aust. J. Chem. 1964 $17,1028$.

(11) Dolphin, D; Johnson, A. W.; Leng, J.; van den Broek, P. J. Chem. Soc. (C) 1966, 880.

(12) Johnson, A. W.; Kay, I. T. J. Chem. Soc. 1965, 1620.

(13) Fuhrop, J.; Smith, K. M. Laboratory Methods. In Porphyrins and Metalloporphyrins; Smith, K. M., Ed.; Elsevier: Amsterdam, 1975.

(14) Shulga, A. M.; Ponomarev, G. V. Khim. Geterotsikl. Soedin. 1988, N3, 339 .
(15) Gurinovich, G. P.; Zenkevich, E. I.; Shulga, A. M.; Sagun, E. I.; Suisalu, A. J. Appl. Spectrosc. 1984, 41, 1044.

(16) Smith, K. M.; Busset, G. M. F.; Bushell, M. J. Bioorg. Chem. 1980, $9,1$.

(17) Adler, A. D.; Longo, F. R.; Finarelli, J. D.; Goldmacher, J.; Assour, J.; Korsakoff, L. J. Org. Chem. 1967, 32, 476.

(18) Whitlock, H. W.; Hanauer, R.; Oester, M. Y.; Bower, B. K. J. Am. Chem. Soc. 1969, 91, 7485.

(19) Spaulding, L. D.; Andrews, L. C.; Williams, G. J. B. J. Am. Chem. Soc. 1977, 99, 6918.

(20) Miller, J. R.; Dorough, G. D. J. Am. Chem. Soc. 1952, 74, 3977.

(21) Gust, D.; Moore, T. A.; Moore, A. L.; Kang, H. K.; DeGraziano,

J. M.; Liddell, P. A.; Seely, G. R. J. Phys. Chem. 1993, 97, 13637.

(22) Zenkevich E. I.; Shulga A. M.; Chernook A. V.; Sagun E. I.; Gurinovich G. P. Khim. Phys. 1989, 8, 812.

(23) Rempel, U.; von Maltzan, B.; von Borczyskowski, C. Chem. Phys. Lett. 1990, 169, 347.

(24) Fulton, R. L.; Gouterman, M. J. Chem. Phys. 1964, 41, 2280.

(25) Lendzian, F.; von Maltzan, B. Chem. Phys. Lett. 1991, 180, 191.

(26) Knop, J. V.; Fuhrhop, J. Z. Naturforsch. 1970, 25b, 729.

(27) Rempel, U.; von Maltzan, B.; von Borczyskowski, C. J. Lumin. 1991, $48 \& 49,415$.

(28) Zenkevich, E. I.; Shulga, A. M.; Chernook, A. V.; Rempel, U.; von Borczyskowski, C. SPIE 1995, 2370, 126

(29) Meyer, S. Diploma Thesis, Freie Universität Berlin, 1992.

JP951108H 